\title{
Fórum: aborto en Brasil, Colombia y Uruguay
}

En los últimos años, el tema del aborto ascendió a la cima del debate político en varios países de América Latina. En especial Uruguay, con la propuesta de Proyecto de Ley de Defensa de la Salud Reproductiva, y Brasil, con el juicio de una acción para autorizar la interrupción de la gestación en casos de feto con anencefalia en el Supremo Tribunal Federal (STF), fueron los principales protagonistas de este escenario político. La importancia de estos dos eventos no se resume a las tentativas locales de cambio de la legislación. El ejemplo de Uruguay y de Brasil debe ser entendido como experiencias exitosas de resistir a un panorama creciente de revisión de legislaciones liberales sobre aborto, en especial a partir de los cambios políticos ocurridos en los Estados Unidos en los últimos años. Así como crece la comprensión del derecho al aborto como una extensión de las libertades individuales y, consecuentemente, como un tema de derechos humanos, aumenta también la intransigencia religiosa por considerarlo un acto de asesinato contra el feto.

Es en este escenario político tenso de expansión y garantía de las libertades individuales y de aumento de la influencia religiosa en el ordenamiento legislativo de los países latino-americanos, donde los tres artículos que componen este Fórum sobre el aborto se insertan. Los artículos discuten la realidad política y sanitaria de Brasil, de Colombia y de Uruguay. Las autoras son protagonistas locales y regionales del proceso de revisión de las legislaciones de aborto.

El primer artículo La Situación del Aborto en Colombia: Entre la Ilegalidad y la Realidad, de Ana Cristina González Veléz, médica, Directora Nacional de Salud Pública de Colombia, presenta un panorama legislativo absolutamente restrictivo en la región. Colombia corresponde a un $0,4 \%$ de la legislación mundial que prohíbe el aborto en todas las situaciones, inclusive en casos de riesgo de vida para la mujer o de violación. Vélez discute la ambigüedad de esta legislación en un país asolado por la violencia y por la desigualdad, donde las mujeres ricas tienen acceso al aborto seguro y las mujeres pobres arriesgan sus vidas en situaciones de aborto inseguro.

El segundo artículo La Experiencia de Uruguay: El Proyecto de Ley de Defensa de la Salud Reproductiva, de Mónica Xavier, médica, senadora y autora del proyecto que propuso la revisión de la ley uruguaya en 2004, presenta las principales propuestas del proyecto que movilizó a América Latina durante su votación. El proyecto de ley, después de haber sido aprobado en la Cámara de los Diputados, fue vencido en el Senado Federal. En caso de que hubiese sido aprobado, representaría la primera legislación francamente liberal en la región. El hecho de que Uruguay sea uno de los países más intensamente laicos en su ordenamiento jurídico y legislativo no debe ser olvidado para la comprensión de la experiencia relatada por Xavier.

El tercer artículo Aborto e Inviabilidad Fetal: El Debate Brasileño, de Debora Diniz, antropóloga, es una de las principales responsables por la acción de anencefalia presentada al STF en 2004, discute los principales argumentos éticos y jurídicos para la propuesta de la acción judicial. Por más que la acción esté restringida a la anencefalia, una malformación que acomete a una de cada mil gestaciones, el proceso de discusión provocado por la acción judicial abrió camino para una extensa polémica sobre el carácter punitivo del aborto en Brasil.

Los tres artículos presentan diferentes expresiones de un tema persistente para la salud pública y, más recientemente, para el debate bioético latinoamericano. América Latina posee una de las legislaciones más restrictivas sobre el aborto en el mundo. El aborto inseguro figura entre la tercera y cuarta causa de mortalidad materna en gran parte de los países, como una clara indicación de la urgencia del debate sanitario y ético. El objetivo es que este Fórum sobre el aborto fortalezca el debate público, laico y razonable sobre un tema que, al mismo tiempo, provoca nuestras certezas morales y nuestro compromiso con las libertades individuales y la salud pública. 